\title{
Characteristics of retrograde amnesia for CS preexposure
}

\author{
James F. Briggs ${ }^{1} \cdot$ Brian P. Olson ${ }^{1}$
}

Published online: 8 February 2017

(C) Psychonomic Society, Inc. 2017

\begin{abstract}
Two experiments using rats evaluated the susceptibility of CS preexposure to retrograde amnesia induced by the protein synthesis inhibitor cycloheximide and tested whether amnesia for CS preexposure shares similar characteristics with amnesia for other memories. In Experiment 1, rats received cycloheximide either immediately, 60 minutes, or 120 minutes after preexposure. Following preexposure, rats received fear conditioning. When later tested, the subjects that received the amnestic treatment shortly after preexposure showed no CS preexposure effect (i.e., no reduction of fear). The amnesia for CS preexposure was attenuated with longer post-preexposure delays, showing a temporal gradient. In Experiment 2, following the replication of amnesia for CS preexposure, the amnestic treatment was readministered to the rats prior to testing. It was demonstrated that the amnestic-preexposure memory could be recovered (i.e., readministration of the drug alleviated the amnesia for CS preexposure). These two experiments show that memories for CS preexposure are susceptible to retrograde amnesia and share similar characteristics with memories for original acquisition and extinction. The results are explained using a retrieval hypothesis of retrograde amnesia.
\end{abstract}

Keywords Fear conditioning · Latent inhibition · Memory · Retrieval

Recent research on experimentally induced retrograde amnesia has challenged the once dominant consolidation theory of

James F. Briggs

briggsj@susqu.edu

1 Department of Psychology, Susquehanna University, Selinsgrove, PA 17870, USA memory. The consolidation view proposes that the formation of a memory for newly acquired information takes time to stabilize because of changes in neural mechanisms, both synaptic and systemic. During consolidation, the memory is labile and in a vulnerable state until it is fully encoded and stored (Dudai, 2004; McGaugh, 2000; Miller \& Matzel, 2006). Evidence for the consolidation theory comes from the timedependent feature of retrograde amnesia (i.e., forgetting events that occurred prior to the amnestic insult). Newly formed memories are more vulnerable to disruption than older memories that have had more time to consolidate and are typically unaffected (Duncan, 1949; Judge \& Quartermain, 1982; Mactutus, Ferek, \& Riccio, 1980; Spear \& Riccio, 1994). Thus, the consolidation theory describes amnesia as an interruption in the encoding and storage processes, with older memories protected from disruption because they are fully fixated.

Evidence challenging the consolidation theory arises from research showing that memories that have been previously stored or consolidated could once again become labile and susceptible to disruption upon reactivation (Mactutus, Riccio, \& Ferek, 1979; Misanin, Miller, \& Lewis, 1968; Nader, Schafe, \& LeDoux, 2000; for review, see Riccio, Millin, \& Bogart, 2006). The hypothesis here is that when a previously formed memory is reactivated by a reminder cue, it once again becomes labile and susceptible to disruption while undergoing a "reconsolidation" process (Przybyslawski \& Sara, 1997). Thus, reactivating the memory predisposes it to once again be susceptible to an amnestic agent because of its active state.

In addition to research showing that "older" reactivated memories once again become susceptible to disruption, research showing that reexposure to the amnestic agent prior to testing alleviates amnesia also challenges the consolidation theory. The reversibility of experimentally induced amnesia 
by reexposure has been demonstrated using traditional amnestic agents including electroconvulsive shock (Thompson \& Neely, 1970) and hypothermia (Hinderliter, Webster, \& Riccio, 1975; Mactutus \& Riccio, 1978), as well as more contemporary protein synthesis inhibitors (Bradley \& Galal, 1988; Briggs \& Olson, 2013; Gisquet-Verrier et al., 2015; Millin \& Newman, 2008). That an amnestic memory could be recovered by reexposure to the treatment is particularly problematic for the consolidation view, which posits that amnestic treatments interfere with the encoding process, thus making the memory inaccessible. In addition, Ryan, Roy, Pignatelli, Arons, and Tonegawa (2015) recently reversed retrograde amnesia induced by protein synthesis inhibition using direct optogenetic activation of the engram cells, demonstrating that the memory is formed under protein synthesis inhibition.

The majority of research on the characteristics of retrograde amnesia (i.e., the temporal gradient and recovery induced by reexposure to the amnestic agent) has been conducted using traditional learning paradigms that involve some type of reinforcement. However, retrograde amnesia for extinction learning has recently been reported to have similar characteristics to retrograde amnesia for original acquisition (Briggs \& Riccio, 2007). In extinction, cues (conditioned stimuli; CS) that have been previously paired with a biologically relevant reinforcer (unconditioned stimuli; US) are presented without the outcome, which leads to a reduction in responding (conditioned response; CR). Extinction learning is now considered new learning rather than a breakdown of the original association. Demonstrating this is evidence showing that the original response spontaneously recovers over time (Pavlov, 1927) and that extinction learning is context specific (Bouton \& Bolles, 1979; see also Bouton, 1993, 2004). That is, extinction is attenuated if the cue-only exposure is conducted in a separate context from original conditioning or testing. Additional evidence for extinction as new learning comes from research demonstrating that extinction is susceptible to disruption using a number of amnestic agents, including hypothermia (Briggs \& Riccio, 2007; Fava \& Riccio, 2014), ethanol (Bisby et al., 2015; Lattal, 2007), an NMDA antagonist (Falls, Miserendino, \& Davis, 1992), a sodium channel blocker (Eisenberg, Kobilo, Berman, \& Dudai, 2003), and protein synthesis inhibitors (Berman \& Dudai, 2001; Briggs \& Olson, 2013; Pedreira \& Maldonado, 2003; Power, Berlau, McGaugh, \& Steward, 2006; Sandusky, Flint, \& McNay, 2012; Vianna, Szapiro, McGaugh, Median, \& Izquierdo, 2001). That extinction can be disrupted and forgotten while leaving the original acquisition memory intact suggests that extinction involves new learning that forms a separate competing memory. Moreover, Briggs and Riccio (2007) showed that amnesia for extinction shares characteristics (i.e., a temporal gradient and reexposure to the amnestic agent alleviating amnesia for extinction) with amnesia for original acquisition memories.

Similar to extinction, CS preexposure (also referred to as latent inhibition) involves learning that takes place without an explicit reinforcer; however, the cues-only exposure occurs before training in CS preexposure, rather than following training as in extinction. The CS preexposure effect is a deficit in the acquisition or expression of an association between familiar cues (conditioned stimuli) and a biologically relevant event (unconditioned stimuli) as the result of having been previously exposed to the cues without the reinforcer (Lubow \& Moore, 1959). Although the CS preexposure effect has often been referred to as latent inhibition, the term is known to be a misnomer. Preexposure to a cue does pass the retardation of learning test for inhibition but fails to pass the summation test (Rescorla, 1971). Behaviorally, similar to extinction, CS preexposure also causes a reduction in the conditioned response. CS preexposure has also been shown to be context specific using a variety of learning paradigms (Bouton \& Bolles, 1979; Channell \& Hall, 1983; Lovibond, Preston, \& Mackintosh, 1984; Maes, 2002; Miller, Laborda, Polack, \& Miguez, 2015; Westbrook, Jones, Bailey, \& Harris, 2000). In addition, the context specificity of CS preexposure has been suggested to result from retrieval failure of the non-reinforced cue exposure (see Bouton, 1993), and that a new competing association may be formed during CS preexposure similar to that of extinction (see Miller et al., 2015; Schauz \& Koch, 2000). Moreover, similar to extinction, CS preexposure has been shown to be vulnerable to disruption by the NMDA receptor antagonists AP-5 (Schauz \& Koch, 2000) and MK801 (Traverso, Ruiz, \& De la Casa, 2003).

Given that extinction and CS preexposure involve similar manipulations and share similar characteristics, our aim here was to determine whether the characteristics of retrograde amnesia for CS preexposure were similar to retrograde amnesia for original acquisition memories and extinction memories. Specifically, using the protein synthesis cycloheximide as the amnestic treatment, we tested whether CS preexposure was susceptible to retrograde amnesia, as well as investigated whether the amnestic effect follows a temporal gradient observed in both original acquisition memories and extinction memories (Experiment 1). Another aim was to determine whether reexposure to the amnestic agent following retrograde amnesia for CS preexposure would reverse forgetting (Experiment 2). We hypothesized that amnesia for CS preexposure would be time dependent and that amnesia for CS preexposure would be alleviated by reexposure to the amnestic agent, given similar results have been obtained for extinction learning. 


\section{Experiment 1}

As mentioned above, retrograde amnesia for original acquisition memories and extinction memories is time dependent. That is, the severity of memory loss is inversely related to the time between the learning episode and the amnestic treatment, with more amnesia observed with short learning-treatment delays and less forgetting with longer learning-treatment delays. If retrograde amnesia for CS preexposure shares this time dependent feature to those of original learning and extinction, there should be less memory impairment as the delay between the preexposure and the cycloheximide amnesia treatment increases.

\section{Method}

Subjects Forty-eight experimentally naïve, adult female and male Long-Evans hooded rats, obtained from Susquehanna University's animal facility breeding colony, served as subjects. An equal number of females and males were randomly assigned to each group. Subjects were approximately 85 days old at the start of the experiment. The female's average weight was $275 \mathrm{~g}$, and the male's average weight was $460 \mathrm{~g}$. Rats were singly housed with free access to food and water, and were maintained on a 12/12 hr light/dark cycle. All experimental sessions took place during the light portion of the photocycle and at the same time each day.

Apparatus Preexposure, training, and testing were conducted in a $40 \times 20 \times 22 \mathrm{~cm}$ white-black passive avoidance chamber (Ugo Basile Model 7551) with a grid floor (3 mm diameter stainless steel bars spaced $1.2 \mathrm{~cm}$ apart, center to center). The passive avoidance chamber was made of Plexiglas and was divided into two compartments of equal size by a sliding door. The white compartment had a transparent Plexiglas lid, and the black compartment had an opaque black Plexiglas lid. Footshocks were delivered through the grid floor via a constant current scrambling circuit located in the apparatus controller. The control unit also records the cross latency with a 0.1 -second resolution. The passive avoidance chamber was located in a $4 \times 5 \mathrm{~m}$ room with white walls. Standard fluorescent lighting illuminated the room.

Procedure Prior to the beginning of the experiment, all rats were handled for approximately 5 minutes on two consecutive days before being weighed and randomly assigned to one of six groups. Twenty-four hours after handling, five groups received a single preexposure trial to induce the CS preexposure effect. During preexposure, each rat was transported into the testing room in its home cage that was placed on a counter for 15 seconds. The rat was then removed from its home cage, and after being placed on the experimenter's arm for 15 seconds, was put into the white compartment of the passive avoidance chamber facing away from the closed sliding door. After 15 seconds, the sliding door separating the two compartments opened automatically, and the latency in seconds for the rat to cross into the black compartment (tilted floor connects a circuit) was automatically recorded. Once the rat crossed into the black compartment, the door automatically closed, and the rat was confined to the black compartment for 12 minutes. The parameters chosen for preexposure were similar to those of previous work and pilot studies that demonstrated effective CS preexposure effects (Briggs, Toth, Olson, \& Lappierre, 2015). Following preexposure, the rat was removed from the black compartment, placed in its home cage, and returned to the colony room. A sixth fear only control group (fear) did not receive preexposure. The design of the experiment is summarized in Table 1.

Following the CS preexposure session, three experimental preexposure groups received the amnestic treatment $(1.0 \mathrm{mg} / \mathrm{kg}$ i.p. of cycloheximide, premixed concentration of $0.1 \%$ [Oxoid Ltd.]) either immediately, 60 minutes, or 120 minutes after being removed from the black compartment (groups CHX-0, CHX-60, CHX-120, respectively) to assess a temporal gradient of retrograde amnesia for the CS preexposure memory. The CHX- 0 animals received the injection immediately while in the experimental context; the CHX60 and CHX-120 delayed animals were returned to the colony room during the delay and received the injection in the colony room. A saline control group received an equivalent volume $(1.0 \mathrm{mg} / \mathrm{kg})$ i.p. injection of physiological saline $(0.9 \%) \mathrm{im}$ mediately after the preexposure session while in the experimental context.

Twenty-four hours after the preexposure session (48 hours after handling for the fear control group), all groups received a single punishment training trial. Training was similar to preexposure except that a footshock was delivered after the rats crossed into the black compartment. During training, each rat was brought into the experimental context and the home cage was placed on a counter for 15 seconds. The rat was then removed from the cage and placed on the experimenter's arm for 15 seconds. The rat was then placed into the white compartment facing away from the closed sliding door. After 15 seconds, the sliding door separating the two compartments automatically opened, and the latency in seconds for the rat to cross into the black compartment was automatically recorded. Once the rat crossed into the black compartment the door automatically closed, and after a 2 -second delay, a single inescapable footshock ( 1 second, $0.8 \mathrm{~mA}$ ) was delivered. Twelve seconds after the shock, the rat was removed from the black compartment, placed in its home cage, and was returned to the colony room.

Twenty-four hours after the training session, all groups underwent passive-avoidance testing. Test trials were conducted identically to training trials, except that no shock was delivered upon entering the black compartment, and the rat 
Table 1 Experimental design for Experiment 1

\begin{tabular}{|c|c|c|c|c|c|c|c|}
\hline Group & Preexposure & Delay & $\mathrm{CHX}$ & $-24 h r-$ & Training & $-24 h r-$ & Test \\
\hline Fear & No & - & No & & Yes & & Yes \\
\hline CSPre & Yes & - & No & & Yes & & Yes \\
\hline CHX-0 & Yes & $0 \mathrm{~min}$ & Yes & & Yes & & Yes \\
\hline CHX-60 & Yes & $60 \mathrm{~min}$ & Yes & & Yes & & Yes \\
\hline CHX-120 & Yes & $120 \mathrm{~min}$ & Yes & & Yes & & Yes \\
\hline Saline & Yes & $0 \min$ & Saline & & Yes & & Yes \\
\hline
\end{tabular}

Note. CSPre $=\mathrm{CS}$ preexposure $\mathrm{CHX}=$ cycloheximide

was immediately removed from the black side once the door automatically closed. Testing lasted for 300 seconds or until the rat crossed into the black compartment. Latency to cross to the black side at test was automatically recorded as the dependent measure.

\section{Results}

Preexposure Rats in all five groups that received preexposure exhibited short cross-through latencies with group means ranging from 16.3 seconds for group CSPre to 24.4 seconds for the saline group. Mean cross-through latencies for groups CHX-0, CHX-60, and CHX-120 were 18.8, 20.7, and 23.9 seconds, respectively. A $2 \times 5$ (Sex $\times$ Group) analysis of variance (ANOVA) revealed a nonsignificant main effect of sex, $F(1,30)=.45, p=.51, \eta_{\mathrm{p}}{ }^{2}=.02$, and a nonsignificant main effect of group, $F(4,30)=.73, p=.58, \eta_{\mathrm{p}}{ }^{2}=.09$. The ANOVA also revealed a nonsignificant Sex $\times$ Group interaction, $F(4,30)=1.89, p=.14, \eta_{\mathrm{p}}{ }^{2}=.20$. Thus, all subjects exhibited similar cross latencies during preexposure.

Training Rats in all six groups exhibited short cross-through latencies at training with group means ranging from $8.2 \mathrm{sec}-$ onds for group saline to 23.1 seconds for the fear group. Mean cross-through latencies for groups CSPre, CHX-0, CHX-60, and CHX-120 were 9.5, 15.6, 16.6, and 13.7 seconds, respectively. A $2 \times 6$ (Sex $\times$ Group) ANOVA revealed a nonsignificant main effect of $\operatorname{sex}, F(1,36)=2.74, p=.11, \eta_{\mathrm{p}}{ }^{2}=.07$, and a nonsignificant main effect of group, $F(5,36)=1.29, p=.29$, $\eta_{\mathrm{p}}{ }^{2}=.15$. The ANOVA also revealed a nonsignificant Sex $\times$ Group interaction, $F(5,36)=.66, p=.66, \eta_{\mathrm{p}}{ }^{2}=.08$. Thus, all subjects exhibited similar cross latencies during training.

Testing Figure 1 shows the mean cross-through latencies for all six groups at testing. As can be seen, the fear control group had a spatial avoidance score that was longer than the CSPre group. In addition, the performance of the $\mathrm{CHX}-0$ group was similar to the fear group and greater than the CSPre group, thus demonstrating retrograde amnesia for CS preexposure. The group that received the amnesia treatment 60 minutes after preexposure (CHX-60) also showed as much avoidance as the CHX-0 group. More important, the group that received the protein synthesis inhibitor 120 minutes after preexposure (CHX-120) had a similar latency score as group CSPre, and was different from both the fear group and the CHX-0 group. This demonstrates a time-dependent feature for retrograde amnesia for CS preexposure; that is, more impairment of the preexposure as the delay between preexposure to protein synthesis inhibitor treatment increases. Finally, the saline control group showed that the increased level of avoidance observed in groups $\mathrm{CHX}-0$ and $\mathrm{CHX}-60$ was not due to stress or a disruption of processing from the injection alone, as this group had a latency score similar to the CSPre group.

These results were confirmed by a $2 \times 6$ (Sex $\times$ Group) ANOVA that revealed a significant main effect of group, $F(5$, 36) $\left.=6.15, p<.001, \eta_{\mathrm{p}}{ }^{2}=.46\right)$. The ANOVA revealed a nonsignificant main effect of sex, $F(1,36)=1.86, p=.18$, $\eta_{\mathrm{p}}{ }^{2}=.05$, and a nonsignificant Sex $\times$ Group interaction, $F(5$, 36) $=.51, p=.77, \eta_{\mathrm{p}}{ }^{2}=.07$. Tukey post hoc tests confirmed that the preexposure (CSPre) produced less avoidance compared to the Fear group $(p=.009, d=2.22)$. In addition, the

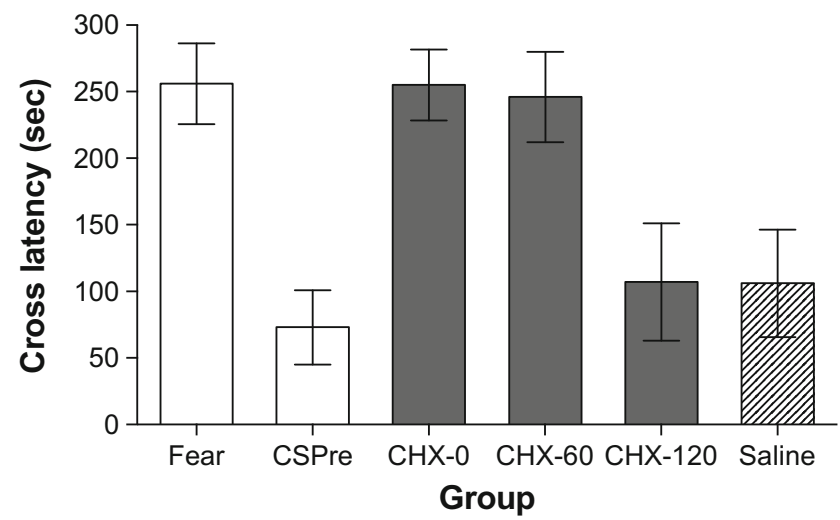

Fig. 1 Mean $( \pm S E M)$ cross-through test latencies for all groups. Open bars represent the fear and CS preexposure (CSPre) control groups. Shaded bars represent the experimental groups. Increased cross latency scores for the group that received cycloheximide immediately following preexposure $(\mathrm{CHX}-0)$, as compared to the preexposure group (CSPre), represents retrograde amnesia for CS preexposure. Group $\mathrm{CHX}-120$ demonstrates that with longer preexposure to $\mathrm{CHX}$ injection delays, the retrograde amnesia for CS preexposure is attenuated (i.e., temporal gradient). Group saline (slashed bar) shows that an injection alone had no effect on the retrograde amnesia for CS preexposure 
CHX groups that received the amnestic treatment immediately $(\mathrm{CHX}-0)$ and 60 minutes $(\mathrm{CHX}-60)$ following preexposure showed significantly longer latency scores than did the CSPre group ( $p=.009, d=2.36 ; p=.015, d=1.98$, respectively), and both groups were similar to the fear group ( $p \mathrm{~s}=$ $1.00, d \mathrm{~s}<.11)$. The longer post-preexposure delay $\mathrm{CHX}$ group (CHX-120) had a latency score similar to the CSPre group ( $p=.983, d=.32$ ) and was borderline significantly shorter than the fear group $(p=.051, d=1.39)$ and the CHX-0 group ( $p=.053, d=1.44$ ), and had a marginally significant shorter score than the CHX-60 group ( $p=.079, d$ $=1.25)$. Post hoc tests also confirmed that the saline control group had latency scores that were significantly shorter than those of the fear group ( $p=.048, d=1.49$ ), and the CHX-0 group ( $p=.050, d=1.58$ ) was marginally shorter that the CHX-60 group ( $p=.075, d=1.34)$ and was similar to the CSPre $(p=.985, d=.33)$ and CHX-120 $(p=1.00, d<.01)$ groups.

\section{Discussion}

The results demonstrate that CS preexposure is susceptible to cycloheximide-induced retrograde amnesia, as well as showing that the memory impairment is time dependent. These results indicate that memories for CS preexposure share a temporal gradient, as seen in memories for original acquisition and extinction. Moreover, the results suggest that CS preexposure is a form of new learning similar to extinction, producing an independent memory that may compete with the association as suggested by others (Miller et al., 2015; Schauz \& Koch, 2000).

These results of a temporal gradient for amnesia of CS preexposure can be explained using a retrieval-oriented hypothesis of retrograde amnesia described by a modified state dependent retention effect (Gisquet-Verrier et al., 2015; Hinderliter et al., 1975; Riccio et al., 2006). According to a retrieval-oriented hypothesis, there is a period of time after acquisition when the newly learned information is processed. If an amnestic agent is presented during processing, the memory is encoded with the altered internal context produced by the amnestic agent. Therefore, if tested in the normal state, there will be a mismatch between the cues, and the memory would be inaccessible. However, if the amnestic treatment is administered following a long-enough postacquisition delay, the memory will have sufficient time to become encoded in a normal state, thus producing the temporal gradient.

Thus, in Experiment 1, administering cycloheximide immediately or 60 minutes after preexposure changed the general state of the animal (see Gisquet-Verrier et al., 2015) and the memory for CS preexposure was formed while the rat was in an altered internal state; however, testing occurred while the animal was back in a normal state. Delaying the injection of cycloheximide by 120 minutes allowed time for the preexposure memory to become fully stored before altering the internal context, resulting in the expression of the memory for CS preexposure at testing.

\section{Experiment 2}

In the second experiment, we investigated whether retrograde amnesia for CS preexposure could be reversed by readministering the amnestic treatment to the rats (i.e., injecting a second dose prior to testing). As mentioned earlier, retrograde amnesia can be attenuated by reexposing the subject to the amnestic agent prior to testing, favoring a retrievaloriented view of amnesia. Thus, in this experiment, the animals were given a second dose of cycloheximide prior to testing to assess whether the amnesia for preexposure could be alleviated. Reversal of the forgetting would further support the retrieval-oriented account of retrograde amnesia for CS preexposure.

\section{Method}

Subjects Forty experimentally naïve, adult female and male Long-Evans hooded rats served as subjects. The animals were obtained and maintained as in Experiment 1. An equal number of females and males were randomly assigned to each group. Subjects were approximately 110 days old at the start of the experiment. The female's average weight was $301 \mathrm{~g}$, and the male's average weight was $480 \mathrm{~g}$.

Apparatus The apparatus and context was the same as that used in Experiment 1.

Procedure All handling, preexposure, injections, training, and testing were identical to Experiment 1, except where noted.

After being handled and weighed, the rats were randomly assigned to one of five groups. Twenty-four hours after handling, four groups received a single preexposure trial as described in Experiment 1. A fear control group did not receive preexposure. Immediately following preexposure, three experimental CS preexposure groups (CHX, ReCHX, ReSal) received the amnestic treatment as described in Experiment 1. The fear control group and a CS preexposure (CSPre) control group did not receive the amnestic treatment. The design of the experiment is summarized in Table 2.

Twenty-four hours after preexposure, all animals were trained as in Experiment 1. Twenty-four hours after punishment training, all animals were tested for passive avoidance. Twenty minutes prior to testing, one group of rats ( $\mathrm{ReCHX})$ that received the amnestic treatment was given a second dose of cycloheximide, similar to the first injection, to reactivate the memory of preexposure. A reexposed saline control group 
Table 2 Experimental design for Experiment 2

\begin{tabular}{|c|c|c|c|c|c|c|c|}
\hline Group & Preexposure & CHX & $-24 h r-$ & Training & $-24 h r-$ & Reexpose & Test \\
\hline Fear & No & No & & Yes & & No & Yes \\
\hline CSPre & Yes & No & & Yes & & No & Yes \\
\hline CHX & Yes & Yes & & Yes & & No & Yes \\
\hline ReCHX & Yes & Yes & & Yes & & Yes & Yes \\
\hline ReSal & Yes & Yes & & Yes & & Saline & Yes \\
\hline
\end{tabular}

Note . CSPre $=\mathrm{CS}$ preexposure $\mathrm{CHX}=$ cycloheximide $; \mathrm{Re}=$ reexposure; $\mathrm{Sal}=$ saline

(ReSal) received a similar physiological saline injection twenty minutes prior to test.

\section{Results}

Preexposure Rats in all four groups that received preexposure exhibited short cross-through latencies with group means ranging from 17.7 seconds for group CSPre to 29.3 seconds for the CHX group. Mean cross-through latencies for groups ReCHX and ReSal were 19.2 and 21.8 seconds, respectively. A $2 \times 4$ (Sex $\times$ Group) ANOVA revealed a nonsignificant main effect of sex, $F(1,24)=.79, p=.38, \eta_{\mathrm{p}}{ }^{2}=.03$, and a nonsignificant main effect of group, $F(3,24)=1.32, p=.29$, $\eta_{\mathrm{p}}{ }^{2}=.14$. The ANOVA also revealed a nonsignificant Sex $\times$ Group interaction, $F(3,24)=.55, p=.65, \eta_{\mathrm{p}}{ }^{2}=.07$. Thus, all subjects exhibited similar cross latencies during preexposure.

Training Rats in all five groups exhibited short cross-through latencies at training with group means ranging from $10.3 \mathrm{sec}-$ onds for group ReCHX to 27.2 seconds for the fear group. Mean cross-through latencies for groups CSPre, CHX, and ReSal were 18.4, 15.5, and 15.1 seconds, respectively. A $2 \times$ 5 (Sex $\times$ Group) ANOVA revealed a nonsignificant main effect of sex, $F(1,30)=.07, p=.79, \eta_{\mathrm{p}}{ }^{2}<.01$, and a nonsignificant main effect of group, $F(4,30)=1.85, p=.15, \eta_{\mathrm{p}}{ }^{2}=$ .19. The ANOVA also revealed a nonsignificant Sex $\times$ Group interaction, $F(4,30)=1.95, p=.13, \eta_{\mathrm{p}}{ }^{2}=.20$. Thus, all subjects exhibited similar cross latencies during training.

Testing Figure 2 shows the mean cross-through latencies for all five groups at testing. As can be seen, the fear control group had a spatial avoidance score that was longer than the CSPre group. In addition, the performance of the CHX group was similar to the fear group and greater than the CSPre group, thus replicating retrograde amnesia for CS preexposure. More importantly, the group that received the second amnesia treatment $(\mathrm{ReCHX})$ showed as much avoidance as the preexposure only control group (CSPre), thus demonstrating that reexposure to the amnestic agent attenuated the retrograde amnesia for a CS preexposure memory. In addition, the group that received a second injection of saline prior to testing (ReSal) had avoidance scores comparable to the Fear and the preexposure amnestic (CHX) group, demonstrating that the injection alone did not disrupt performance or reduce fear.

These results were confirmed by a $2 \times 5$ (Sex $\times$ Group) ANOVA that revealed a significant main effect of group, $F(4$, $30)=7.93, p<.001, \eta_{\mathrm{p}}{ }^{2}=.51$. The ANOVA revealed a nonsignificant main effect of sex, $F(1,30)=.17, p=.69$, $\eta_{\mathrm{p}}{ }^{2}<.01$, and a nonsignificant Sex $\times$ Group interaction, $F(4$, $30)=1.54, p=.22, \eta_{\mathrm{p}}{ }^{2}=.17$. Tukey post hoc tests confirmed that the preexposure (CSPre) group produced less avoidance compared to the fear group ( $p=.020, d=1.63$ ). In addition, the CHX group that received the amnestic treatment immediately following preexposure (CHX) showed significantly longer latency scores than the CSPre group ( $p=.042, d=1.57)$, and was similar to the fear group ( $p=.998, d=.12)$. The reexposed CHX group ( $\mathrm{ReCHX}$ ) had a latency score similar to the CSPre group ( $p=.992, d=.29$ ) and a significantly shorter score than the fear group ( $p=.006, d=1.67)$ and the CHX group ( $p=.013, d=1.61)$. Confirming that the second

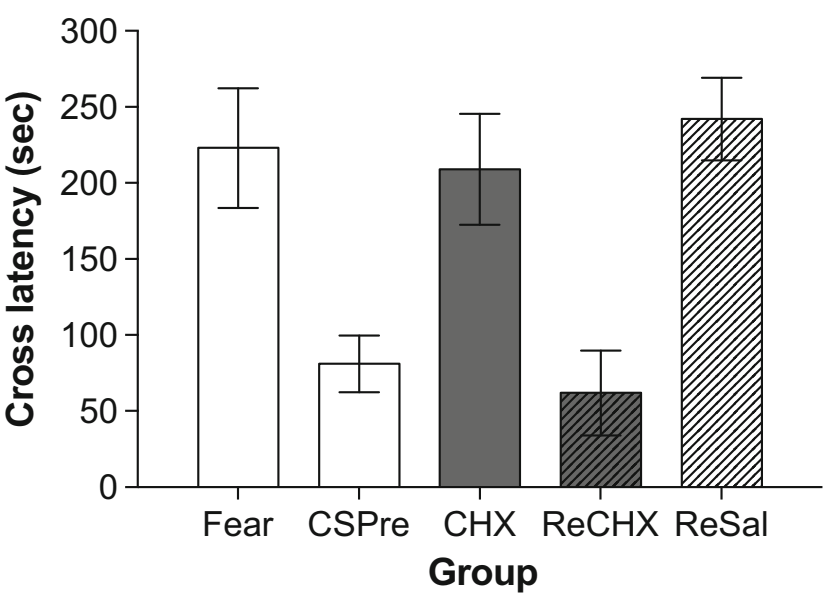

Fig. 2 Mean $( \pm S E M)$ cross-through test latencies for all groups. Open bars represent the no-preexposure fear and CS preexposure (CSPre) control groups. Shaded bars represent the experimental groups. Increased cross latency scores for the group that received cycloheximide immediately following preexposure $(C H X)$, as compared to the CS preexposure group (CSPre), represents retrograde amnesia for $\mathrm{CS}$ preexposure. Group $\mathrm{ReCHX}$ received a second dose of cycloheximide 20 minutes prior to testing. The lower cross latency demonstrates a statedependent effect (i.e., the retrograde amnesia for CS preexposure is attenuated). Group ReSal (slashed bar) shows that a second injection of saline had no effect on the return of the CS preexposure memory 
injection alone did not cause the reduction of fear, post hoc tests also showed that the reexposed saline control group (ReSal) had latency scores similar to the fear and CHX groups ( $p=.991, d=.20 ; p=.943, d=.36$, respectively) and a longer latency score compared to the CSPre ( $p=.006, d=2.45)$ and $\operatorname{ReCHX}(p=.002, d=2.31)$ groups.

\section{Discussion}

The results of Experiment 2 replicated the susceptibility of CS preexposure to retrograde amnesia, as well as demonstrated that retrograde amnesia for CS preexposure could be reversed by reexposing the subjects to the amnestic agent prior to testing. The rats that received a second dose of cycloheximide before testing performed similar to the CS preexposure animals. This recovery of the CS preexposure memory is similar to the recovery observed with original acquisition memories and extinction memories. Furthermore, the reversibility of retrograde amnesia provides evidence that CS preexposure represents a separate learned event that forms an independent memory.

Although a saline reexposure control group was included, one could question whether the cycloheximide given just prior to test had some motor effects or caused a reduction of fear by inhibiting processing. If the cycloheximide caused a decrement in movement it would be expected that the animals would take longer to cross or not cross at all; however, the rats had shorter latencies to cross, thus ruling out a kinetic effect. If the second dose of cycloheximide inhibited processing, one could argue that this caused the shorter cross latencies due to the inability to process fear. However, previous research from our lab, using the same second dose of cycloheximide 20 minutes prior to testing and a similar paradigm, showed recovery of an old reactivated fear memory that increased latency scores and the recovery of an extinction of fear memory that decreased latency scores (Briggs \& Olson, 2013). Thus, because of the differential effects, it is unlikely that any inhibited processing caused by the treatment can account for the low latencies observed by the reexposed cycloheximide group. Moreover, these differential effects on latency scores rule out any speculation that the agent may have increased arousal or activity, thus producing shorter latencies. It should be pointed out that others have reported an increase in locomotor activity in mice following higher doses of cycloheximide; however, they demonstrated that the increase in activity did not account for decreased latencies in a stepdown passive avoidance task (Gutwein, Quartermain, \& McEwen, 1974).

Another consideration for the results observed in Experiment 2 could be in terms of state dependency with respect to training. That is, the fear associations learned during training could be state dependent and therefore readministering the drug lead to a failure to express fear during testing (resulting in the low latency scores for the reexposed cycloheximide group). Although not included in this study, others testing for state-dependent effects have shown that administering the amnestic agents hypothermia (Hinderliter et al., 1975) and cycloheximide (Quinton, 1971) prior to testing alone had no effects on performance in a passiveavoidance task. Therefore, a training-to-testing statedependent effect appears to be an unlikely explanation of our results.

The results of Experiment 2 can be explained using a retrieval-oriented hypothesis for retrograde amnesia, which postulates an encoding-retrieval mismatch in cues (GisquetVerrier et al., 2015; Hinderliter et al., 1975; Riccio et al., 2006). As described earlier, cycloheximide administered shortly after CS preexposure produces retrograde amnesia for preexposure at test due to the mismatch between internal cues during encoding and testing. However, reintroducing the cycloheximide just prior to testing returned the internal cues, which allowed for the retrieval of the CS preexposure memory.

\section{General discussion}

These findings demonstrated that exposure to the protein synthesis inhibitor cycloheximide shortly after preexposure to the to-be-conditioned cues produced retrograde amnesia for the CS preexposure effect. These results are consistent with other reports that show blocking of CS preexposure by treatments either before (Schauz \& Koch, 2000) or after (Traverso et al., 2003) preexposure. The current studies extend earlier research by demonstrating a temporal gradient of retrograde amnesia for CS preexposure as well as determining that the amnesia is reversible by reexposure to the amnestic agent. These characteristics of retrograde amnesia are similar to those seen in original acquisition memories and extinction memories. These results further suggest that, similar to extinction learning, CS preexposure forms a new competing association that is susceptible to disruption (Miller et al., 2015; Schauz \& Koch, 2000).

The results of the experiments presented here suggest that retrograde amnesia for CS preexposure can be explained by a retrieval-oriented theory of retrograde amnesia, in which the forgetting is not produced by the inhibition of protein synthesis but rather by a state-dependent-like effect caused by the amnestic agent cycloheximide. This explanation is similar to the context specificity of CS preexposure described earlier. Recently, Miller and colleagues (2015), using a lick suppression paradigm with rats, reported the CS preexposure effect (i.e., less fear) when rats were preexposed and tested in the same environment. However, rats that were preexposed in one particular environment and tested in a different environment showed significantly more conditioned fear, thus a change in 
context alleviated the preexposure effect. This is conceptually similar to a change in internal contextual cues caused by the amnestic agent in our experiments. When cycloheximide was administered shortly after the nonreinforced preexposure, the memory was encoded in an altered state. At testing when the animals returned to their normal state, the appropriate retrieval cues were not available, causing a mismatch between the internal contexts. Moreover, in our Experiment 2, reexposing the animals to the agent prior to testing alleviated forgetting by restoring the internal cues, thus allowing the retrieval of the preexposure memory, similar to testing occurring in the same external environments.

That the amnesia for CS preexposure reported here is reversible is inconsistent with the dominant consolidation view of memory. What remains to be determined is whether the recovery of the amnestic preexposure memory is permanently recovered following reexposure, or would the memory once again be inaccessible once the animal returns to a normal state? Using hypothermia as the amnestic agent to obtain retrograde amnesia for an extinction memory, Briggs and Riccio (2007) found that reexposure to deep body cooling that recovered the forgotten extinction memory was dependent on the core body temperature at test. That is, when the animals were allowed to rewarm following reexposure, the extinction memory once again was forgotten (see also Hinderliter et al., 1975). In addition, the current studies did not assess whether spontaneous recovery of the amnestic CS preexposure memory would occur. Squire and Barondes (1972) reported spontaneous recovery of memory from cycloheximide-induced amnesia for a discrimination task in mice. Albeit a different species and paradigm, that spontaneous recovery has been shown using the protein synthesis inhibitor cycloheximide deems the issue worthy of further investigation.

Acknowledgements Partial funding of this research was provided by a Susquehanna University Committee on Faculty Scholarship grant to JFB. We thank Dr. David C. Riccio for his insightful comments on early drafts of this manuscript.

\section{Compliance with ethical standards}

Conflict of interest The authors report no conflict of interest.

\section{References}

Berman, D. E., \& Dudai, Y. (2001). Memory extinction, learning anew, and learning the new: Dissociation in the molecular machinery of learning in cortex. Science, 291, 2417-2419.

Bisby, J. A., King, J. A., Sulpizio, V., Degeilh, F., Curran, H. V., \& Burgess, N. (2015). Extinction learning is slower, weaker and less context specific after alcohol. Neurobiology of Learning and Memory, 125, 55-62.
Bouton, M. E. (1993). Context, time, and memory retrieval in the interference paradigms of Pavlovian learning. Physiological Bulletin, $114,80-99$.

Bouton, M. E. (2004). Context and behavioral processes in extinction. Learning \& Memory, 11, 485-494.

Bouton, M. E., \& Bolles, R. C. (1979). Contextual control of the extinction of conditioned fear. Learning and Motivation, 10, 445-466.

Bradley, P. M., \& Galal, K. M. (1988). State-dependent recall can be induced by protein synthesis inhibition: Behavioral and morphological observations. Developmental Brain Research, 40, 243-251.

Briggs, J. F., \& Olson, B. P. (2013). Reexposure to the amnestic agent alleviates cycloheximide-induced retrograde amnesia for reactivated and extinction memories. Learning \& Memory, 20, 285-288.

Briggs, J. F., \& Riccio, D. C. (2007). Retrograde amnesia for extinction: Similarities with amnesia for original acquisition memories. Learning \& Behavior, 35, 131-140.

Briggs, J. F., Toth, T. A., Olson, B. P., \& Lappierre, J. G. (2015). Transfer of memory retrieval cues attenuates the context specificity of latent inhibition. Journal of Behavioral and Neuroscience Research, 12, $40-44$.

Channell, S., \& Hall, G. (1983). Contextual effects in latent inhibition with an appetitive conditioning procedure. Animal Learning \& Behavior, 11, 67-74.

Dudai, Y. (2004). The neurobiology of consolidations, or, how stable is the engram? Annual Review of Psychology, 55, 51-86.

Duncan, C. P. (1949). The retroactive effect of electroshock on learning. Journal of Comparative and Physiological Psychology, 42, 32-44.

Eisenberg, M., Kobilo, T., Berman, D. E., \& Dudai, Y. (2003). Stability of retrieved memory: Inverse correlation with trace dominance. Science, 301, 1102-1104.

Falls, W. A., Miserendino, M. J. D., \& Davis, M. (1992). Extinction of fear-potentiated startle: Blockade by infusion of an NMDA antagonist into the amygdala. The Journal of Neuroscience, 12, 854-863.

Fava, D. A., \& Riccio, D. C. (2014). Mild hypothermia can disrupt extinction learning but not original conditioning. Physiology \& Behavior, 125, 54-56.

Gisquet-Verrier, P., Lynch, J. F., III, Cutolo, P., Toledano, D., Ulmen, A., Jasnow, A. M., \& Riccio, D. C. (2015). Integration of new information with active memory accounts for retrograde amnesia: A challenge to the consolidation/reconsolidation hypothesis? The Journal of Neuroscience, 35, 11623-11633.

Gutwein, B. M., Quartermain, D., \& McEwen, B. S. (1974). Dissociation of cycloheximide's effects on activity from its effects on memory. Pharmacology, Biochemistry and Behavior, 2, 753-756.

Hinderliter, C. F., Webster, T., \& Riccio, D. C. (1975). Amnesia induced by hypothermia as a function of treatment-test interval and recooling in rats. Animal Learning \& Behavior, 3, 257-263.

Judge, M. E., \& Quartermain, D. (1982). Characteristics of retrograde amnesia following reactivation of memory in mice. Physiology \& Behavior, 28, 585-590.

Lattal, K. M. (2007). Effects of ethanol on the encoding, consolidation, and expression of extinction following contextual fear conditioning. Behavioral Neuroscience, 121, 1280-1292.

Lovibond, P. F., Preston, G. C., \& Mackintosh, N. J. (1984). Context specificity of conditioning, extinction, and latent inhibition. Journal of Experimental Psychology: Animal Behavior Processes, 10, 360-375.

Lubow, R. E., \& Moore, A. U. (1959). Latent inhibition: The effect of nonreinforced pre-exposure to the conditional stimulus. Journal of Comparative and Physiological Psychology, 52, 415-419.

Mactutus, C. F., Ferek, J. M., \& Riccio, D. C. (1980). Amnesia induced by hyperthermia: An unusually profound, yet reversible, memory loss. Behavioral and Neural Biology, 30, 260-277.

Mactutus, C. F., \& Riccio, D. C. (1978). Hypothermia-induced retrograde amnesia: Role of body temperature in memory retrieval. Physiological Psychology, 6, 18-22. 
Mactutus, C. F., Riccio, D. C., \& Ferek, J. M. (1979). Retrograde amnesia for (old) reactivated memory: Some anomalous characteristics. Science, 204, 1319-1320.

Maes, J. H. R. (2002). No sex differences in contextual control over the expression of latent inhibition and extinction in Pavlovian fear conditioning in rats. Neurobiology of Learning and Memory, 78, 258278.

McGaugh, J. L. (2000). Memory-A century of consolidation. Science, 204, 248-251.

Miller, R. R., Laborda, M. A., Polack, C. W., \& Miguez, G. (2015). Comparing the context specificity of extinction and latent inhibition. Learning and Behavior, 43, 384-395.

Miller, R. R., \& Matzel, L. D. (2006). Retrieval failure versus memory loss in experimental amnesia: Definitions and processes. Learning \& Memory, 13, 491-497.

Millin, P. M., \& Newman, E. N. (2008). A comparison of the effects of state and non-state reminder treatments on morphine statedependency and cycloheximide-induced retrograde amnesia in rats. Journal of Behavioral and Neuroscience Research, 6, 6-14.

Misanin, J. R., Miller, R. R., \& Lewis, D. J. (1968). Retrograde amnesia produced by electroconvulsive shock after reactivation of a consolidated memory trace. Science, 160, 554-555.

Nader, K., Schafe, G. E., \& LeDoux, J. E. (2000). Fear memories require protein synthesis in the amygdala for reconsolidation after retrieval. Nature, 406, 722-726.

Pavlov, I. P. (1927). Conditioned reflexes: An investigation of the physiological activity of the cerebral cortex. London, England: Oxford University Press.

Pedreira, M. E., \& Maldonado, H. (2003). Protein synthesis subserves reconsolidation or extinction depending on reminder duration. Neuron, 38, 863-869.

Power, A. E., Berlau, D. J., McGaugh, J. L., \& Steward, O. (2006). Anisomycin infused into the hippocampus fails to block "reconsolidation" but impairs extinction: The role of re-exposure duration. Learning \& Memory, 13, 27-34.

Przybyslawski, J., \& Sara, S. J. (1997). Reconsolidation of memory after its reactivation. Behavioural Brain Research, 84, 241-246.
Quinton, E. E. (1971). The cycloheximide-induced amnesia gradient of a passive avoidance task. Psychonomic Science, 25, 295-296.

Rescorla, R. A. (1971). Summation and retardation tests of latent inhibition. Journal of Comparative and Physiological Psychology, 75, $77-81$.

Riccio, D. C., Millin, P. M., \& Bogart, A. R. (2006). Reconsolidation: A brief history, a retrieval view, and some recent issues. Learning \& Memory, 13, 536-544.

Ryan, T. J., Roy, D. S., Pignatelli, M., Arons, A., \& Tonegawa, S. (2015). Engram cells retain memory under retrograde amnesia. Science, 348, 1007-1013.

Sandusky, L. A., Flint, R. W., Jr., \& McNay, E. C. (2012). Effects of the protein synthesis inhibitor cycloheximide on anxiety-like extinction behavior in an animal model of post-traumatic stress. Behavioural Brain Research, 231, 208-212.

Schauz, C., \& Koch, M. (2000). Blockade of NMDA receptors in the amygdala prevents latent inhibition of fear-conditioning. Learning \& Memory, 7, 393-399.

Spear, N. E., \& Riccio, D. C. (1994). Memory: Phenomena and principles. Boston, MA: Allyn \& Bacon.

Squire, L. R., \& Barondes, S. H. (1972). Variable decay of memory and its recovery in cycloheximide-treated mice. Proceedings of the National Academy of Sciences, 69, 1416-1420.

Thompson, C. I., \& Neely, J. E. (1970). Dissociated learning in rats produced by electroconvulsive shock. Physiology \& Behavior, 5, $783-786$

Traverso, L. M., Ruiz, G., \& De la Casa, L. G. (2003). Latent inhibition disruption by MK-801 in a conditioned taste-aversion paradigm. Neurobiology of Learning and Memory, 80, 140-146.

Vianna, M. R. M., Szapiro, G., McGaugh, J. L., Median, J. H., \& Izquierdo, I. (2001). Retrieval of memory for fear-motivated training initiates extinction requiring protein synthesis in the rat hippocampus. Proceedings of the National Academy of Sciences, 98, 1225112254.

Westbrook, R. F., Jones, M. L., Bailey, G. K., \& Harris, J. A. (2000). Contextual control over conditioned responding in a latent inhibition paradigm. Journal of Experimental Psychology: Animal Behavior Processes, 26, 157-173. 